UDC 582.632+547.913.5+547.914.4

\title{
6-HYDROXYISOCARYOPHYLLENE AND ISOCARYOPHYLLENIC ACID FROM BIRCH VEGETATIVE BUDS
}

\author{
(c) D.N. Vedernikov ${ }^{I^{*}}$, S.V. Teplyakova ${ }^{1}$, O.V. Khoroshilova ${ }^{2}$
}

\author{
${ }^{1}$ St. Petersburg State Forest Technical University named after S.M.Kirov, Institutsky \\ per., 5, St. Petersburg, 194021 (Russia), e-mail: dimitriy-4@yandex.ru \\ ${ }^{2}$ Saint-Petersburg State University, Institute of Chemistry of St. Petersburg State \\ University, Universitetsky Prospekt, 26, Peterhof, Petrodvortsovy borough, St. \\ Petersburg, North-West Federal District, 199034. (Russia), \\ e-mail: o_khorosh@mail.ru
}

The new isocaryophyllene derivatives: 6-hydroxyisocaryophyllene [(1R,4Z,6R,9S)-8-methylene-11,11-dimethylbicyclo[7.2.0]undec-4-ene-6-ol], epoxide of 6-hydroxyisocaryophyllene [(6R)-hydroxy-(4R,5S)-epoxyisocaryophyllene [(1R,4R,5S,6R,9S)-4.5-epoxy-8-methylene-11,11-dimethylbicyclo[7.2.0]undeco-4-ene-6-ol], (6R)-acetoxyisocaryophyllene [(6R)-acetoxy-(1R,4Z,9S)-8-methylene-11,11-dimethylbicyclo[7.2.0]undec-4-ene], isocaryphyllenic acid [(1R,4E,9S)4carboxy-8-methylene-11,11-dimethylbicyclo[7.2.0]undeco-4-ene] were first detected in the birch vegetative buds. 6Hydroxyisocaryophyllene and epoxide of 6-hydroxyisocaryophyllene are isolated by from the Betula pendula Roth. birch buds etheric extract by chromatography on silica gel. (6R)-Acetoxyisocaryophyllene was synthesized. The structure of 6hydroxyisocaryophyllene and epoxide of 6-hydroxyisocaryophyllene isolated from the buds were determined by NMR spectroscopy. Caryophyllenic acids are isolated from the ether extract with an aqueous solution of alkali. Caryophyllenic acids are separated by chromatography on silica gel. The structures of caryophyllenic acid and isocaryphyllenic acid isolated from the Betula grandifolia Litv., B. albo-sinensis Burk., B. fusca Pall.ex Georg, B. obscura A. Kotula, B. litwinowii Doluch., B. hallii Howell, $B$. grandifolia Litv. birch buds were determined by X-ray diffraction analysis. The physico-chemical characteristics and NMR data of 6-hydroxyisocaryophyllene, epoxide of 6-hydroxyisocaryophyllene and all the isolated acids are given. The obtained mixtures of compounds were analyzed by gas chromatography - mass spectrometry (GC-MS). The gas chromatographic retention indices of all identified compounds were determined.

Keywords: 6-hydroxyisocaryophyllene, epoxide of 6-hydroxyisocaryophyllene, isocaryophyllenic, caryophyllenic acid, vegetative buds of birch, NMR spectroscopy, X-ray diffraction analysis, gas chromatography - mass spectrometry.

\section{Introduction}

We have earlier reported the hydrocarbon extract sesquiterpene alcohols composition of pendent white birch (Betula pendula Roth.) vegetative buds. The fraction contains 6-hydroxycaryophyllene, 6-hydroxyhumulene, 14-hydroxycarophyllene [1]. The main components of the investigated birch 14-hydroxy-caryophyllene, 6hydroxycarophyllene and their esters. But on the GC-MS chromatogram, there was an intense peak of an unknown compound whose mass spectrum was similar to the mass spectrum of 6-hydroxycaryophyllene. The same pattern was observed in the analysis the birch buds Betula grandifolia Litv., B. albo-sinensis Burk., B. fusca Pall.ex

Vedernikov Dmitriy Nikolaevich - Department of Technology of Wood Chemical Products, Wood Chemistry and Biotechnology, Professor, D.Sc., Associate Professor, e-mail: dimitriy-4@yandex.ru

Teplyakova Svetlana Vitalievna - Department of Technology of Wood Chemical Products, Wood Chemistry and Biotechnology, graduate student, e-mail:chooh@bk.ru Khoroshilova Olesya Valerievna - graduate student, specialist of RSA, e-mail: o_khorosh@mail.ru
Georg, B. obscura A. Kotula, B. litwinowii Doluch. , birch of golden, bog birch $B$. hallii Howell, B. grandifolia Litv. extract obtained by extraction with ether. Two peaks of other compounds were present on chromatograms. Whose mass spectra were little distinguishable. The aim of this work was to establish the structure of compounds that give similar mass spectra.

\footnotetext{
* Corresponding author.
} 


\section{Experimental}

Vegetative buds of pendent white birch Betula pendula (100 g (65 g absolutely dry buds) of buds) were collected in April 2016 in the Kirishi district of the Leningrad Region. Buds of bog birch B. hallii (28 g (17.4 g a.d.b.)) were harvested in March 2017 in the arboretum of St. Petersburg Forestry University. The wet, crushed buds were extracted with methyl tert-butyl ether (MTBE) in a Soxhlet apparatus. The yield of extract from a.d.b.of pendent white birch was $41 \%$, of the bog birch buds $-42 \%$. The extracts were treated with a $1 \%$ aqueous solution of $\mathrm{NaOH}$ to remove acids. The yield of acids from the pendent white birch extract was $33 \%$, the acid yield from the bog birch extract $-87 \%$. The obtained neutral substances of the extract $(17.8 \mathrm{~g})$ of pendent white birch buds and the acids of bog birch extract (6.36 g) were separated by preparative liquid chromatography on silica gel with gradient elution using petroleum benzine (PE) (boiling range $40-70{ }^{\circ} \mathrm{C}$ ) as an eluent with the addition of up to $30 \%$ MTBE. The fraction of sesquiterpene alcohols $(8.35 \%$ of the MTBE extract) eluted from the PE column supplemented with 5\% MTBE. The fraction was re-chromatographed into individual compounds. Unknown sesquiterpene alcohol (0.120 g) (1) (eluted earlier than other sesquiterpene alcohols: 6-hydroxycaryophyllene and 6hydroxy-gumulene). The fraction of oxides of sesquiterpene alcohols eluted with the addition of 7\% MTBE.

Sesquiterpene acids eluted PE with an addition of 25 to $30 \%$ MTBE. The acid (3) (2.21 g) was eluted before the acid (4) (2.42 g). The acid fractions were methylated with diazomethane before analyzing by gas chromatography-mass spectrometry (GLC-MS) since the acids did not appear as peaks in the chromatogram.

The chromatographic analysis was carried out using a 6850A Agilent chromato-mass spectrometer (Agilent Technologies, Inc.) with a model G2629A gas chromatograph equipped with a model G2577A HP5973 Network selective mass spectrometry detector. The flow rate of carrier gas (He) was $1 \mathrm{~mL}$ per min. Samples of $2 \mu \mathrm{L}$ were injected in the split mode at a ratio of $20: 1$. The injector temperature was $270^{\circ} \mathrm{C}$. The transfer line were kept at $270{ }^{\circ} \mathrm{C}$. The quadrupole temperature was $270 \mathrm{C}$. The ion source was kept at $230{ }^{\circ} \mathrm{C}$. The ionizing energy was $70 \mathrm{eV}$. Mass range was from 40 to $550 \mathrm{~m} / \mathrm{z}$.

To fractionate samples, a HP-5MS quartz column $(30 \mathrm{~m} \times 0.25 \mathrm{~mm}$; film thickness $0.25 \mu \mathrm{m})$ with a $5 \%$ phenylmethyl-siloxane stationery phase was used. The thermostat temperature was programmed to increase from 100 to $270{ }^{\circ} \mathrm{C}$ at a rate of $5^{\circ} \mathrm{C} \mathrm{min}^{-1}$. The oven was held at this temperature for $30 \mathrm{~min}$.

The gas chromatographic retention indices (RI) of the analyzed substances were determined using the retention indices of $n$-alkanes $\left(\mathrm{C}_{16}-\mathrm{C}_{19}\right)$ as standard compounds (Sigma-Aldrich)). The standard compounds were chosen so that the retention times of the studied substances fell between those of the reference alkanes. Retention indices were calculated following the determination of the coefficients of the following equation: $\mathrm{RI}=\mathrm{a} \tau^{2}+\mathrm{b} \tau+\mathrm{c}$, where RI and $\tau$ represent the retention index and retention time, respectively. All calculations were performed using an Advanced Grapher program (version 2.08).

High resolution mass spectrum (HR-ESI) was recorded on a Bruker-micrOTOF instrument using an electrospray method. The scanning interval is $50-1200 \mathrm{~m} / \mathrm{z}$. The ion polarity is positive, the voltage of the ion source capillary is $4500 \mathrm{~V}$, the gas pressure at spraying is 0.4 bar, and the dry gas flow rate is $4.01 / \mathrm{min}$. The solvent was methanol.

NMR spectra were recorded using a NMR spectrometer Jeol ECX-400A (400 and $100 \mathrm{MHz}$ for ${ }^{1} \mathrm{H}$ and ${ }^{13} \mathrm{C}$

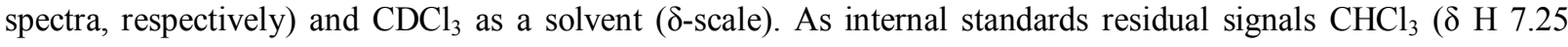
ppm) were used.

IR spectra were recorded on a FTIR-8400S Shimadzu instrument using the FT-IR reflection technique.

Optical rotation angle was determined on the device: Automatic Polarimeter AA65. Solvent-chloroform. The length of the cuvette is $3 \mathrm{~cm}$.

Thin layer chromatography was performed on Merck Silica gel 60 F254 plates. The spots on the TLC plates were sprayed with a $10 \%$ solution of sulfuric acid in ethanol with the addition of vanillin.

For single crystal $X$-ray diffraction experiment crystals were fixed on a micro mount and placed on an Agilent Technologies SuperNova (4), (5) using $\mathrm{CuK} \alpha$ and MoK $\alpha$ monochromated radiation diffractometers, respectively. All of crystals were measured at a temperature of $100 \mathrm{~K}$. The structures were solved by the Direct methods and refined by means of the SHELXL program [2] incorporated in the OLEX2 program package [3]. The crystallographic data and some parameters of refinement are placed in Table 1. Empirical absorption correction was applied in CrysAlisProprogram complex [4] using spherical harmonics, implemented in SCALE3 ABSPACK scaling algorithm. Supplementary crystallographic data for this paper have been deposited at Cambridge Crystallographic 
Data Centre (CCDC 1583801. 1583802 for isocaryophyllenic acid (4) and caryophyllenic acid (5), respectively) and can be obtained free of charge via www.ccdc.cam.ac.uk/data_request/cif.

Physic-chemical and Spectral Characteristics of the Extracted Compounds

(6R)-Hydroxyisocaryophyllene [(1R,4Z,6R,9S)-8-methylene-11.11-dimethylbicyclo[7.2.0]undec-4-ene6-ol] (1). Oil, RI= 1642. IR-spectrum $\left(v, \mathrm{sm}^{-1}\right): 3385(\mathrm{OH}), 3057(=\mathrm{CH}), 2953\left(\mathrm{CH}_{2}\right), 2923\left(\mathrm{CH}_{2}\right), 2851\left(\mathrm{CH}_{2}\right), 1713$, 1708, 1633 $\left(\mathrm{C}=\mathrm{CH}_{2}\right), 1462\left(-\mathrm{C}\left(\underline{\mathrm{CH}}_{3}\right)=\mathrm{CH}-\right), 1378,1367,1265,1025(\mathrm{CH}-\mathrm{OH}), 894\left(\mathrm{C}=\mathrm{CH}_{2}\right), 740,704,581$.

Mass-spectrum (m/z): 220 (1), 205 (7), 187 (11), 177(11), 149 (21), 131 (43), 121 (41), 109(74), 107(45), 105 (46), 95(58), 93(54), 91(69), 79(81), 69(79), 41(100).

High resolution mass spectrometry (HR-ESI): $\mathrm{m} / \mathrm{z} 243.1720(100)[\mathrm{M}+\mathrm{Na}]+, 244.1752(16.3)[\mathrm{M}+\mathrm{Na}+1]+$, 245.1782(1.3) [M+Na+2]. Mass calculation $\mathrm{C}_{15} \mathrm{H}_{24} \mathrm{O}: \mathrm{m} / \mathrm{z}$ 243.1725(100), 244.1758(16.2), 245.1792(1.2).

(6R)-Acetoxyisocaryophyllene $\quad[(6 R)$-acetoxy-(1R,4Z,9S)-8-methylene-11.11-dimethylbicyclo[7.2.0]undec-4-ene] (2). Oil, $\mathrm{RI}=1742 .[\alpha]_{\mathrm{D}}{ }^{20}+32.8^{\circ}\left(c=0.945 . \mathrm{CHCl}_{3}\right) . \quad$ IR-spectrum $\left(v, \mathrm{~cm}^{-1}\right): 2950,2929,2859,1737$ $(\mathrm{C}=\mathrm{O}), 1630.1451 .1368 .1242(\mathrm{O}-\mathrm{C}=\mathrm{O}), 1020.964 .888\left(\mathrm{C}=\mathrm{CH}_{2}\right), 850$.

Mass-spectrum (m/z): $262(<1), 247(<1), 220(3), 202(17), 189$ (21), 159(31), 145(23), 133(76), 131(61), 119(32), 109(46), 105(51), 91(63), 79(51), 67(21), 65(14), 55(23), 43(100).

(6R)-hydroxy-(4R,5S)-epoxyisocaryophyllene [(1R,4R,5S,6R,9S)-4.5-epoxy-8-methylene-11.11-dimethylbicyclo[7.2.0] undeco-4-ene-6-ol] (3). Oil, RI=1808.

Mass-spectrum (m/z): $236(<1), 221(2), 205(3), 203(6), 193(4), 189(5), 175(8), 161(12), 147(13), 135$ (14), 121(45), 109(61), 95(76), 82(50), 79(78), 69(100), 55(47), 41(94), 29(18).

High resolution mass spectrometry (HR-ESI): $\mathrm{m} / \mathrm{z}$ 259.1674(100) [M+Na]+; 260.1708(16.5) [M+Na+1]+, 261.1741(2.0) $[\mathrm{M}+\mathrm{Na}+2]+$. Mass calculation $\mathrm{C}_{15} \mathrm{H}_{24} \mathrm{O}_{2}+\mathrm{Na}: \mathrm{m} / \mathrm{z}$ 259.1674(100), 260.1708(16.2), 261.1741(1.2).

${ }^{1} \mathrm{H}$ NMR in $\mathrm{CDCl}_{3}(\delta): 0.99$ (3H, s, H-12), 1.00 (3H, s, H-13), 1.52 (3H, s, H-14), 1.55 (1H, dd, J J-10a $=9.2$,

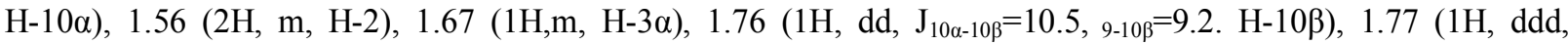
$\left.\mathrm{J}_{1-9}=9.2,{ }_{1-2 \alpha}=11.7,{ }_{1-2 \beta}=3.5, \mathrm{H}-1\right) 1.91\left(1 \mathrm{H}, \mathrm{dd}, \mathrm{J}_{6-7 \alpha}=9.4,7 \alpha-7 \beta=12.0, \mathrm{H}-7 \alpha\right), 1.96\left(1 \mathrm{H}, \mathrm{dd}, \mathrm{J}_{6-7 \beta}=3.4 . \mathrm{H}-7 \beta\right), 2.04(1 \mathrm{H}$,

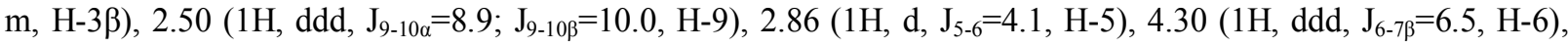

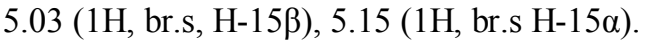

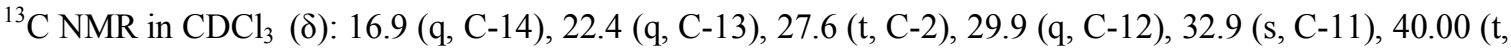
C-3), 40.2 (t, C-10), 41.4 (t, C-7), 46.9 (d, C-9), 49.3 (s, C-4), 55.4 (d, C-1), 64.2(d, C-6), 67.6 (d, C-5), 147.7 (s, C-8), 114.0(t, C-15).

Isocaryophyllenic acid [1R,4E,9S)4-carboxy-8-methylene-11.11-dimethylbicyclo [7.2.0] undeco-4-ene] (4). $\mathrm{Tm}=103-104^{\circ} \mathrm{C}$ (from hexane). RI of methyl ester $-1726 .[\alpha]_{\mathrm{D}}{ }^{26}-46.1^{\circ}\left(c=1.447 . \mathrm{CHCl}_{3}\right)$. IR-spectrum $\left(v, \mathrm{~cm}^{-1}\right)$ : 2947, 2920, 2854, 2650, 2565, 1674(C=C- $\underline{\mathrm{COOH}}), 1635(\mathrm{C}=\mathrm{C}), 1450,1423\left(\mathrm{HRC}=\mathrm{CH}_{2}\right), 1307,1288,1257,1226$, $1199,1188,941,922,887,771,740,532$.

Mass-spectrum of methyl ester (m/z): 248(6), 233(18), 216(6), 201(11), 189(35), 179(63), 173(25), 165(13), 156(2), 147(88.5), 133(76), 119(57), 105(60), 91(100), 79(61), 69(79), 59(14), 53(28).

High resolution mass spectrometry (HR-ESI): m/z 235.1697(100) $[\mathrm{M}+\mathrm{H}]+, 236.1740(16.6)[\mathrm{M}+\mathrm{H}+1]+$, 237.1774(1.3) $[\mathrm{M}+\mathrm{H}+2]+$. Mass calculation $\mathrm{C}_{15} \mathrm{H}_{22} \mathrm{O}_{2}+\mathrm{H}: \mathrm{m} / \mathrm{z}$ 235.1698(100), 236.1732(16.2), 237.1765 (1.2).

TLC: system: hexane-MTBE $=10: 3 . \mathrm{R}_{\mathrm{f}}=0.55$ (pink).

Caryophyllenic acid [1R,4Z,9S)4-carboxy-8-methylene-11.11-dimethylbicyclo [7.2.0]undeco-4-ene] (5). $\mathrm{Tm}=90-91^{\circ} \mathrm{C}$ (from hexane). RI of methyl ester $-1688 .[\alpha]_{\mathrm{D}}{ }^{26}-31.5\left(c=1.642 . \mathrm{CHCl}_{3}\right)$. IR-spectrum $\left(v, \mathrm{~cm}^{-1}\right)$ : $3070,3016,2924,2854,2781,2604,1670(\mathrm{C}=\mathrm{C}-\underline{\mathrm{COOH}}), 1628(\mathrm{C}=\mathrm{C}), 1439,1419\left(\mathrm{HRC}=\mathrm{CH}_{2}\right), 1369,1303,1269$, $1200,1169,956,933,887,783,624,574$.

Mass spectrum of methyl ester (m/z): 248(2), 233(16), 216(6), 201(9), 189(31), 179(60), 173(25), 165(14), 156(3), 147(100), 145(30), 133(62), 119(72), 105(57), 91(96), 79( 80), 69(75), 59(14), 53(28).

High resolution mass spectrometry (HR-ESI): m/z 235.1697(100) $[\mathrm{M}+\mathrm{H}]+, 236.1740(16.6)[\mathrm{M}+\mathrm{H}+1]+$, 237.1774(1.3) $[\mathrm{M}+\mathrm{H}+2]+$. Mass calculation $\mathrm{C}_{15} \mathrm{H}_{22} \mathrm{O}_{2}+\mathrm{H}: \mathrm{m} / \mathrm{z}$ 235.1698(100), 236.1732(16.2), 237.1765(1.2).

TLC: system: hexane-MTBE $=10: 3 . \mathrm{R}_{\mathrm{f}}=0.63$ (lilac).

Caryophyllenic acid pyrazoline methyl ester кислоты (6). $\mathrm{T}_{\text {пл }}=113-115^{\circ} \mathrm{C}$ (from hexane). RI=1731. IR-spectrum $\left(v, \mathrm{~cm}^{-1}\right): 2950,2861,1737,1639,1463,1438,1373,1248,1208,1171,1047,891$.

High resolution mass spectrometry (HR-ESI): m/z 291.2067 (100) [M+H]+; 292.2100(19.6) [M+H+1]+; 293.2133(2) $[\mathrm{M}+\mathrm{H}+2]+$. Mass calculation: $\mathrm{C}_{17} \mathrm{H}_{26} \mathrm{~N}_{2} \mathrm{O}_{2}+\mathrm{H}: \mathrm{m} / \mathrm{z} 291.2103$ (100); 292.2134(18.4); 293.2094(1.6); 
main peaks: $\mathrm{m} / \mathrm{z} 313.1886(100)[\mathrm{M}+\mathrm{Na}]+; 314.1919(20.0)[\mathrm{M}+\mathrm{Na}+1]+; 315.1952(2.0)[\mathrm{M}+\mathrm{Na}+2]+. \mathrm{Mass}$ calculation: $\mathrm{C}_{17} \mathrm{H}_{26} \mathrm{~N}_{2} \mathrm{O}_{2}+\mathrm{Na}: \mathrm{m} / \mathrm{z} 313.1894$ (100); 314.1928(18.4); 315.1961(1.6).

Mass spectrum (m/z): 262 (10), 247(10), 234(5), 219(13), 215(13), 205(10), 203(34), 193(8), 187(20), 173(11), 161(39), 147(47), 133(66), 119(33), 109(20),107(100), 93(57), 91(87), 79(85), 69(39), 41(59).

${ }^{13} \mathrm{C} \mathrm{NMR}$ in $\mathrm{CDCl}_{3}(\delta): 21.9$ q (C-13) 29.8, q (C-12), $23.9 \mathrm{t}(\mathrm{C}-6), 25.9 \mathrm{t}(\mathrm{C}-2), 34.5 \mathrm{~s}(\mathrm{C}-11), 36.3 \mathrm{t}(\mathrm{C}-3)$, $36.4 \mathrm{t}(\mathrm{C}-7), 36.9 \mathrm{t}(\mathrm{C}-10), 36.9 \mathrm{~d}(\mathrm{C}-9), 42.7 \mathrm{~d}(\mathrm{C}-1) 52.0 \mathrm{q}\left(\mathrm{OCH}_{3}\right), 58.8 \mathrm{~d}(\mathrm{C}-5), 83.6 \mathrm{t}\left(\mathrm{CH}_{2}-\mathrm{N}=\mathrm{N}\right), 98.4 \mathrm{~s}(\mathrm{C}-4)$, 111.2 t (C-15), 151.2 s (C-8), $168.0 \mathrm{~s}(\mathrm{C}-14)$.

\section{Results and discussion}

The structure of compound (1) was established on the basis of two-dimensional NMR spectra and analysis of the spin-spin interaction constants. We were compared the NMR spectra of the two compounds, since the mass spectrum (1) practically coincides with the mass spectrum of (6R) -hydroxycaryophyllene [(1R,6R,4E,9S)-8methylene-11,11-dimethylbicyclo[7.2.0] undeco-4-ene-6-ol, RI = 1670]. In the ${ }^{13} \mathrm{C} \mathrm{NMR}$ and ${ }^{13} \mathrm{C}$ NMR spectra of DEPT 135. a similar set of carbon signals associated with different numbers of hydrogen atoms was present, as in the spectrum of 6-hydroxycaryloryllene [5]. In the ${ }^{1} \mathrm{H}$ NMR spectrum, proton signals of three methyl groups with centers at $0.98 ; 0.97 ; 1.62 \mathrm{ppm}$ were observed (Table 1). The last signal belongs to the protons of the $\mathrm{CH}_{3}$-group, which is bonded to the carbon atom $(\mathrm{C}-4)$ of the double bond. The structure also contained an exomethylene group, as evidenced by proton signals at 4.92 and $4.85 \mathrm{ppm}$, trisubstituted double bond (proton signal at $1 \mathrm{H}$ at $5.20 \mathrm{ppm}$ (H-C5)) and adjacent secondary alcohol group (proton signal at $1 \mathrm{H}$ at $4.55 \mathrm{ppm}$ (H-C6)). The proton signal at the carbon atom (C-6) bound to the $\mathrm{OH}$ group was noted as a triplet of doublets, and the proton signal at the double bond carbon atom in the cyclic structure gave the signal as a doublet. Thus, the structure of the compound should have the following fragment:

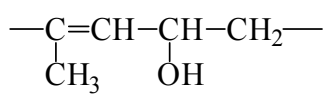

Two doublets of doublets with the intensity of one proton with centers at 2.55 and $2.42 \mathrm{ppm}$ on the ${ }^{1} \mathrm{H}$ NMR spectrum refer to the protons of the methylene group next to the carbon atom with the secondary hydroxyl. The second side of the methylene group should contain a completely substituted carbon atom (C-8) (the absence of the protons interaction of the methylene group with other protons). The displacement of the signals of the protons of the methylene group into a weaker field suggests a close proximity of the exomethylene group. That is, in the structure of the molecule of the compound there is a fragment:<smiles>C=C(C)CC(O)C=C(C)C</smiles>

The isolated compound is a derivative of caryophyllene, since on the ${ }^{1} \mathrm{H}$ NMR spectrum, the signals of methyl groups in the form of singlets with centers of 0.97 and $0.98 \mathrm{ppm}(3 \mathrm{H}-\mathrm{C} 13,3 \mathrm{H}-\mathrm{C} 12)$ proton signals at carbon of two double bonds are visible. One combination of atoms refers to the exomethylene group, and another combination of atoms belongs to the group with trisubstituted carbons, which is characteristic of caryophyllene.

A secondary hydroxyl group is present in the structure of the compound. The hydroxyl group should be located next to the double bond. Two-dimensional COSY NMR spectrum was obtained to confirm the existence of the above assumed fragments, which showed interactions between neighboring hydrogen atoms. Two-dimensional spectrum of $\mathrm{C}-\mathrm{H}$ was obtained to assign hydrogen signals to specific carbon atoms. The fragments found were similar to the (6R)-hydroxycaryophyllene fragments, but chemical shifts and spin-spin interaction constants differed. Thus, $\mathrm{J}_{5-6}$ for hydroxy-caryophyllene is $10.4 \mathrm{~Hz}$, and for the isolated compound it is 7.7. which makes the signal narrower. It was assumed that the isolated compound is (6R)-hydroxyisocaryophyllene.

Two-dimensional NMR spectrum of NOESY was analyzed to confirm the structure. The cross peaks that appeared on the spectrum corresponded to the structure of (6R)-hydroxy-isocaryophyllene (Fig.1). Earlier it was reported that 14-hydroxyisocaryophyllene and isocaryophyllene-14-al were found in essential oils of various birches, including pendent white birch [6]. 


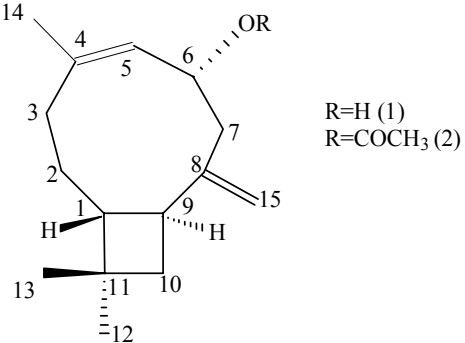

The isolated alcohol was proacetylated with a mixture of acetic anhydride and pyridine and the obtained product (2) was found on the chromatogram of the hydrocarbon extract of the buds, since acetates of sesquiterpene alcohols are present in the buds of birch [7].

The epoxide (3) corresponding to the alcohol (1) is also present in the birch bud extract, and was isolated by preparative chromatography. The epoxy of 6-hydroxycaryophyllene is also present in the extract of the birch buds [7].

$J / \mathrm{Hz}$ : for $(1): 1-9=9.1 ; 1-2 \alpha=11.9 ; 1-2 \beta=3.7$; $2 \alpha-3 \beta=8.9 ; \quad 2 \beta-3 \beta=4.0 ; \quad 2 \alpha-2 \beta=13.8 ; \quad 2 \beta-3 \alpha=4.5 ;$ $3 \alpha-2 \alpha=4.6 ; \quad 3 \alpha-3 \beta=13.6 ; \quad 3 \beta-14=1.1 ; \quad 15 \alpha-15 \beta=1.5$; $5-14=2.0 ; 5-6=7.7 ; 6-7 \beta=3.6 ; 6-7 \alpha=8.4 ; 7 \alpha-7 \beta=13.0$; $9-10 \alpha=9.1 ; 9-10 \beta=9.6 ; 10 \alpha-10 \beta=10.6$;

for (2): $1-9=9.1 ; 1-2 \alpha=11.0 ; 1-2 \beta=4.0 ; 2 \alpha-3 \beta$ $=8.9 ; 2 \beta-3 \beta=4.0 ; 2 \alpha-3 \beta=8.9 ; 2 \alpha-2 \beta=13.6 ; 2 \beta-3 \alpha=4.5$; $2 \alpha-3 \alpha=4.9 ; \quad 3 \alpha-3 \beta=13.2 ; \quad 3 \beta-14=1.1 ; \quad 6-7 \alpha=8.4$; $6-7 \beta=3.6 ; 6-5=7.7 ; 7 \alpha-7 \beta=4.0 ; 9-10 \alpha=9.1 ; 9-10 \beta$ $=10.2 ; 10 \alpha-10 \beta=10.6 ; 15 \beta-7 \alpha=1.2$

The isolated compounds of the bog birch buds are acids, since the compounds were shown on GCMS chromatograms only after preliminary methylation with diazomethane, dissolved in an aqueousalkaline solution when extracting the etheric extract of the buds. Further, the structure of the isolated acids was established by X-ray structural analysis. The analysis showed that both compounds crystallize in $\mathrm{PE}$ at $+4{ }^{\circ} \mathrm{C}$ (Table 2) and form crystals consisting of two conformers in a $1: 1$ ratio (Fig.2. 3).

Two-dimensional spectra of ${ }^{1} \mathrm{H}-{ }^{1} \mathrm{H}$ ROESY, COSY, HMQC, HMBC were taken to establish the correspondence of carbon and hydrogen atoms to the signals on the NMR spectra, The results are shown in Table 3 below and Figures 4 and 5 .

Acids (4) and (5) are geometric isomers that crystallize, forming conformers

The ${ }^{1} \mathrm{H}$ NMR spectrum of compound (5) was similar to the spectrum given for caryophyllenic acid isolated from extracts of a plant of the genus Lichnofora [8].

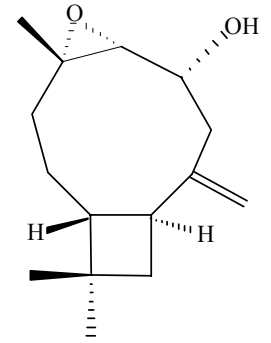

(3)

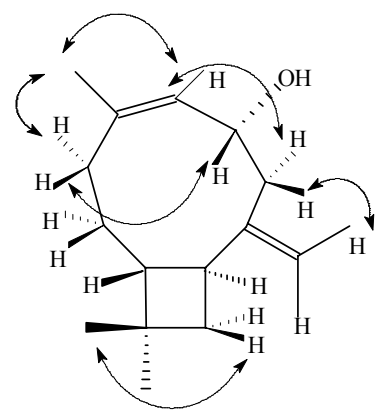

Fig. 1. Selected NOE correlations of the compound (1)

Table 1. Data on the ${ }^{1} \mathrm{H}$ NMR and ${ }^{13} \mathrm{C}$ NMR spectra of the isolated compounds $(1)$ and $(2)(\delta \mathrm{H}, \delta \mathrm{C})$

\begin{tabular}{c|c|c|c|c}
\hline \multirow{2}{*}{$\mathrm{C}$ atom } & \multicolumn{2}{|c|}{1} & \multicolumn{2}{c}{2} \\
\cline { 2 - 5 } & $\delta \mathrm{C}, \mathrm{ppm}$ & $\delta \mathrm{H}, \mathrm{ppm}$ & $\delta \mathrm{C}, \mathrm{ppm}$ & $\delta \mathrm{H}, \mathrm{ppm}$ \\
\hline 1 & $49.4 \mathrm{~d}$ & $1.69 \mathrm{ddd}$ & $50.1 \mathrm{~d}$ & $1.68 \mathrm{ddd}$ \\
2 & $25.4 \mathrm{t}$ & $\alpha 1.62 \mathrm{~m}$ & $25.5 \mathrm{t}$ & $\alpha 1.58 \mathrm{~m}$ \\
& & $\beta 1.52 \mathrm{~m}$ & & $\beta 1.54 \mathrm{~m}$ \\
3 & $29.2 \mathrm{t}$ & $\alpha 1.83 \mathrm{~m}$ & $29.2 \mathrm{t}$ & $\alpha 1.94 \mathrm{~m}$ \\
& & $\beta 2.30 \mathrm{~m}$ & & $\beta 2.44 \mathrm{~m}$ \\
4 & $136.0 \mathrm{~s}$ & - & $138.0 \mathrm{~s}$ & - \\
5 & $130.0 \mathrm{~d}$ & $5.20 \mathrm{~d}$ & $125.5 \mathrm{~d}$ & $5.14 \mathrm{~d}$ \\
6 & $70.9 \mathrm{~d}$ & $4.55 \mathrm{ddd}$ & $72.3 \mathrm{~d}$ & $5.60 \mathrm{ddd}$ \\
7 & $45.4 \mathrm{t}$ & $\alpha 2.55 \mathrm{dd}$ & $42.5 \mathrm{t}$ & $\alpha 2.39 \mathrm{dd}$ \\
& & $\beta 2.42 \mathrm{dd}$ & & $\beta 2.56 \mathrm{dd}$ \\
8 & $151.9 \mathrm{~s}$ & - & $151.0 \mathrm{~s}$ & - \\
9 & $40.3 \mathrm{~d}$ & $2.44 \mathrm{ddd}$ & $39.8 \mathrm{~d}$ & $2.47 \mathrm{ddd}$ \\
10 & $39.7 \mathrm{t}$ & $\alpha 1.53 \mathrm{dd}$ & $39.7 \mathrm{t}$ & $\alpha 1.56 \mathrm{dd}$ \\
& & $\beta 1.72 \mathrm{dd}$ & & $\beta 1.72 \mathrm{dd}$ \\
11 & $33.0 \mathrm{~s}$ & - & $33.0 \mathrm{~s}$ & - \\
12 & $29.9 \mathrm{q}$ & $0.98 \mathrm{~s}$ & $30.1 \mathrm{q}$ & $0.98 \mathrm{~s}$ \\
13 & $23.0 \mathrm{q}$ & $0.97 \mathrm{~s}$ & $23.2 \mathrm{q}$ & $0.99 \mathrm{~s}$ \\
14 & $22.8 \mathrm{q}$ & $1.62 \mathrm{~s}$ & $22.9 \mathrm{q}$ & $1.63 \mathrm{~s}$ \\
15 & $112.3 \mathrm{t}$ & $\alpha 4.92 \mathrm{br} . \mathrm{s}$ & $113.2 \mathrm{t}$ & $\alpha 4.91 \mathrm{br} . \mathrm{s}$ \\
& & $\beta 4.85 \mathrm{br} . \mathrm{s}$ & & $\beta 4.97 \mathrm{br} . \mathrm{s}$ \\
$\mathrm{CH}_{3} \mathrm{COO}$ & - & - & $21.6 \mathrm{q}$ & $2.04 \mathrm{~s}$ \\
$\mathrm{CH}_{3} \mathrm{COO}$ & - & - & $170.5 \mathrm{~s}$ & - \\
\hline
\end{tabular}


Table 2. Summary crystallographic data for (4) and (5)

\begin{tabular}{|c|c|c|}
\hline Compound & (4) & (5) \\
\hline Empirical formula & $\mathrm{C}_{15} \mathrm{H}_{22} \mathrm{O}_{2}$ & $\mathrm{C}_{15} \mathrm{H}_{22} \mathrm{O}_{2}$ \\
\hline Formula weight & Orthorhombic & Monoclinic \\
\hline Temperature/K & $6.1029(3)$ & $9.2537(2)$ \\
\hline Crystal system & $13.0180(5)$ & $11.4795(3)$ \\
\hline Space group & $34.244(2)$ & $13.4148(4)$ \\
\hline $\mathrm{a} / \AA$ & 90 & 90 \\
\hline $\mathrm{b} / \AA$ & 90 & $104.500(3)$ \\
\hline $\mathrm{c} / \AA \AA$ & 90 & 90 \\
\hline$\alpha /^{\circ}$ & $2720.6(2)$ & $1379.64(6)$ \\
\hline$\beta /{ }^{\circ}$ & 234.32 & 234.32 \\
\hline$\gamma /{ }^{\circ}$ & $\mathrm{P} 2_{1} 2_{1} 2_{1}$ & $\mathrm{P} 2_{1}$ \\
\hline Volume $/ \AA^{3}$ & 0.580 & 0.073 \\
\hline Z & $100(2)$ & $100(2)$ \\
\hline$\rho_{\text {calc }} \mathrm{g} / \mathrm{cm}^{3}$ & 8 & 4 \\
\hline$\mu / \mathrm{mm}^{-1}$ & 1.144 & 1.128 \\
\hline $\mathrm{F}(000)$ & $0.15 \times 0.05 \times 0.05$ & $0.8 \times 0.3 \times 0.15$ \\
\hline Crystal size $/ \mathrm{mm}^{3}$ & $\mathrm{CuK} \alpha$ & $\mathrm{MoK} \alpha$ \\
\hline Radiation & 12799 & 30724 \\
\hline Angle range $2 \theta\left(^{\circ}\right)$ & 5365 & 6308 \\
\hline Total reflections & $7.264-144.970$ & $5.998-55.000$ \\
\hline Unique reflections & 4386 & 6133 \\
\hline Reflections with $\mathrm{I} \geq 2 \sigma(\mathrm{I})$ & 0.0721 & 0.0401 \\
\hline$R_{\text {int }}$ & 0.0736 & 0.0265 \\
\hline$R_{\text {sigma }}$ & 0.0747 & 0.0324 \\
\hline S & 0.1916 & 0.0856 \\
\hline$R_{l}[\mathrm{I} \geq 2 \sigma(\mathrm{I})]$ & 0.0926 & 0.0335 \\
\hline$w R_{2}[\mathrm{I} \geq 2 \sigma(\mathrm{I})]$ & 0.2156 & 0.0867 \\
\hline$R_{l}$ [all data] & 1.081 & 1.058 \\
\hline$w R_{2}[$ all data $]$ & $0.46 ;-0.30$ & $0.20 ;-0.18$ \\
\hline \multirow{2}{*}{\multicolumn{3}{|c|}{$\begin{array}{c}\rho_{\text {max }}, \rho_{\min }\left(e / \AA^{3}\right) / \mathrm{e} \AA^{-3} \\
\text { CCDC Number }\end{array}$}} \\
\hline & & \\
\hline $\begin{array}{r}w=1 /\left[\sigma^{2}\left(F_{\mathrm{o}}{ }^{2}\right)\right. \\
\text { where } n \text { is }\end{array}$ & $\begin{array}{l}; w R_{2}=\left\{\Sigma\left[w\left(F_{\mathrm{o}}^{2}-\right.\right.\right. \\
\text { де } P=\left(F_{\mathrm{o}}^{2}+2 F_{\mathrm{c}}{ }^{2}\right)\end{array}$ & $\begin{array}{l}n-p)\}^{1 / 2} \\
\text { meters. }\end{array}$ \\
\hline
\end{tabular}

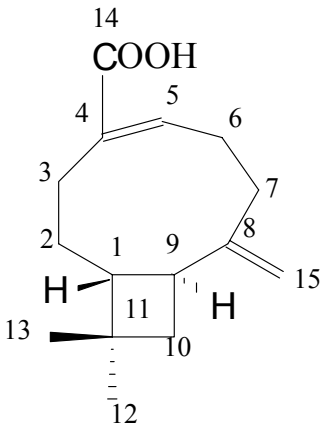

(4)

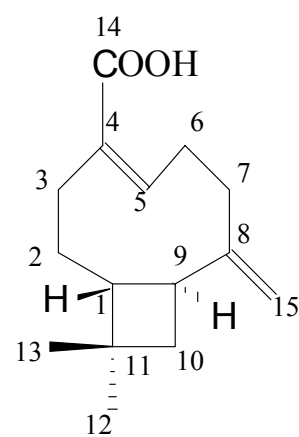

(5)

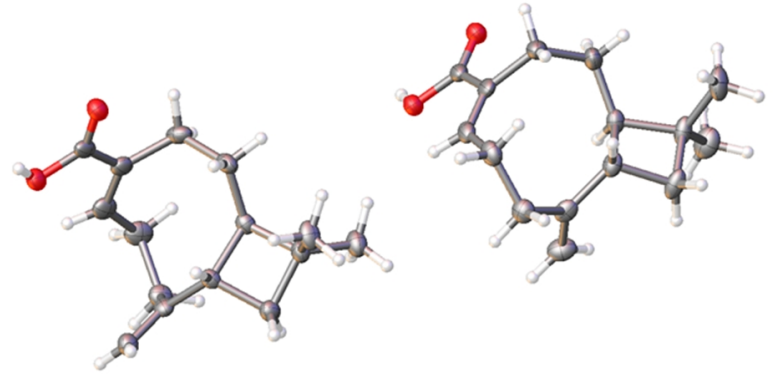

Fig. 2. Conformers (4) according to X-ray diffraction

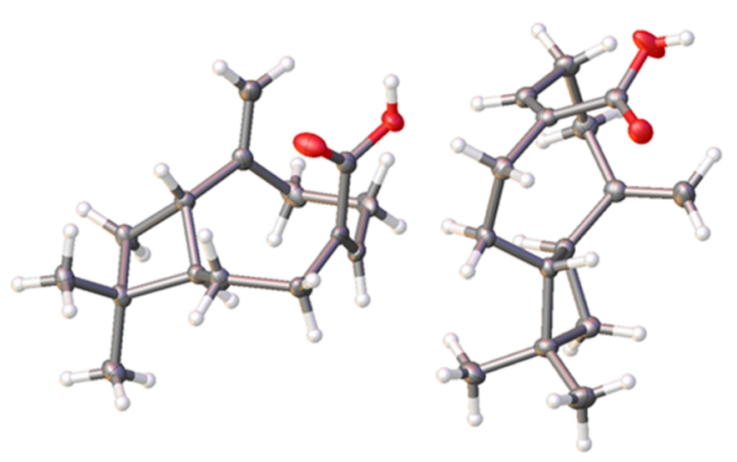

Fig. 3. Conformers (5) 

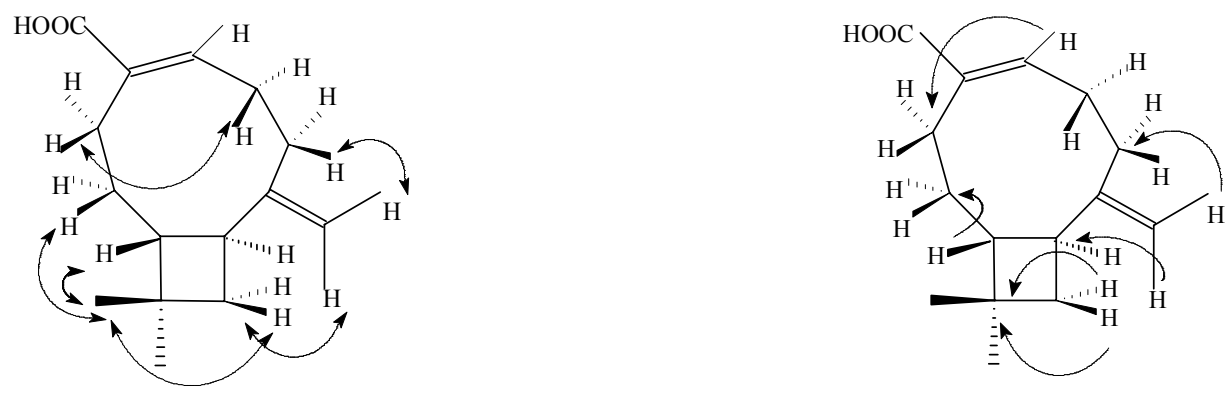

Fig. 4. Selected NOE and HMBC correlations of the compound (4)
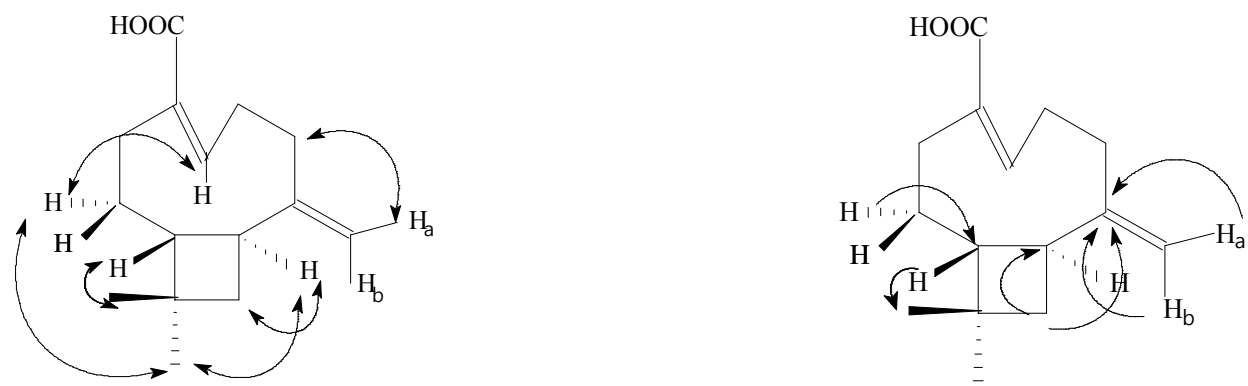

Fig. 5. Selected NOE and HMBC correlations of the compound (5)

Table 3. Data on the ${ }^{1} \mathrm{H}$ NMR and ${ }^{13} \mathrm{C}$ NMR spectra of the compounds (4) and (5)* $(\delta \mathrm{H}, \delta \mathrm{C}, \mathrm{ppm})$

\begin{tabular}{|c|c|c|c|c|}
\hline \multirow{2}{*}{$\mathrm{C}$ atom } & \multicolumn{2}{|c|}{ (4) } & \multicolumn{2}{|c|}{ (5) } \\
\hline & $\delta \mathrm{C}, \mathrm{ppm}$ & $\delta \mathrm{H}, \mathrm{ppm}$ & $\delta \mathrm{C}, \mathrm{ppm}$ & $\delta \mathrm{H}, \mathrm{ppm}$ \\
\hline 1 & $52.1 \mathrm{~d}$ & $1.81 \mathrm{ddd}$ & $51.6 \mathrm{~d}$ & $1.63 \mathrm{ddd}$ \\
\hline 2 & $27.4 \mathrm{t}$ & $\alpha 1.48 \mathrm{~m}$ & $30.0 \mathrm{t}$ & $\alpha 1.66 \mathrm{~m}$ \\
\hline & & $\beta 1.66 \mathrm{~m}$ & & $\beta 1.85 \mathrm{~m}$ \\
\hline 3 & $23.9 \mathrm{t}$ & $\alpha 2.45 \mathrm{~m}$ & $34.8 \mathrm{t}$ & $\alpha 2.68 \mathrm{~m}$ \\
\hline & & $\beta 2.30 \mathrm{~m}$ & & $\beta 2.63 \mathrm{~m}$ \\
\hline 4 & $132.2 \mathrm{~s}$ & - & $130.2 \mathrm{~s}$ & - \\
\hline 5 & $144.9 \mathrm{~d}$ & $7.00 \mathrm{dd}$ & $147.0 \mathrm{~d}$ & 6.23 br. $\mathrm{t}$ \\
\hline 6 & $28.7 \mathrm{t}$ & $\alpha 2.49 \mathrm{~m}$ & $31.2 \mathrm{t}$ & $\alpha 2.23 \mathrm{~m}$ \\
\hline & & $\beta 2.41 \mathrm{~m}$ & & $\beta 3.22 \mathrm{~m}$ \\
\hline 7 & $34.0 \mathrm{t}$ & $\alpha 2.41 \mathrm{~m}$ & $33.5 \mathrm{t}$ & $2.19 \mathrm{~m}$ \\
\hline & & $\beta 2.29 \mathrm{~m}$ & & \\
\hline 8 & $154.6 \mathrm{~s}$ & - & $151.8 \mathrm{~s}$ & - \\
\hline 9 & $40.2 \mathrm{~d}$ & $2.50 \mathrm{ddd}$ & $48.9 \mathrm{~d}$ & $2.46 \mathrm{ddd}$ \\
\hline 10 & $40.3 \mathrm{t}$ & $\alpha 1.74 \mathrm{dd}$ & $40.3 \mathrm{t}$ & $1.59 \mathrm{dd}$ \\
\hline & & $\beta 1.56 \mathrm{dd}$ & & $1.78 \mathrm{dd}$ \\
\hline 11 & $33.4 \mathrm{~s}$ & - & $33.9 \mathrm{~s}$ & - \\
\hline 12 & $30.1 \mathrm{q}$ & $0.99 \mathrm{~s}$ & $30.2 \mathrm{q}$ & $1.00 \mathrm{~s}$ \\
\hline 13 & $23.0 \mathrm{q}$ & $0.96 \mathrm{~s}$ & $22.5 \mathrm{q}$ & $0.98 \mathrm{~s}$ \\
\hline 14 & $173.7 \mathrm{~s}$ & - & $174.3 \mathrm{~s}$ & - \\
\hline 15 & $111.6 \mathrm{t}$ & $\alpha 4.87 \mathrm{~d}$ & $114.3 \mathrm{t}$ & $\alpha 5.01 \mathrm{~d}$ \\
\hline & & $\beta 4.80 \mathrm{~d}$ & & $\beta 4.86 \mathrm{~d}$ \\
\hline
\end{tabular}

${ }^{*} \mathrm{H}$ and ${ }^{13} \mathrm{C}$ NMR spectra were obtained at $50^{\circ} \mathrm{C}$.

$\mathrm{J}, \mathrm{Hz}$ : for (4): $1-2 \alpha=9.4 ; 1-2 \beta=4.0 ; 2 \alpha-3 \beta=11.5 ; 2 \beta-3 \beta=4.2 ; 2 \beta-3 \alpha=12.6 ; 2 \alpha-2 \beta=13.8 ; 3 \alpha-2 \alpha=5.3$; $3 \alpha-3 \beta=13.7 ; 15-15$ ' $=1.5 ; 5-6 \beta=9.3 ; 5-6 \alpha=6.1 ; 6-7 \beta=4.0 ; 6-7 \alpha=8.9 ; 7 \alpha-7 \beta=13.0 ; 1-9=9.7 ; 9-10 \alpha=2.0 ; 9-10 \beta=9.1$; $10 \alpha-10 \beta=10.4$.

J, Hz: for (5): $1-9=8.9 ; 1-2 \alpha=11.0 ; 1 \beta-2 \beta=1.4 ; 2 \beta-3 \alpha=2.5 ; 3 \alpha-2 \alpha=7.0 ; 2 \beta-2 \alpha=9 ; 2 \alpha-3 \beta=13.0 ; 2 \beta-3 \beta=2.0$; $3 \alpha-3 \beta=13.5 ; 5-6 \beta=7.7 ; 5-6 \alpha=7.6 ; 7 \alpha-6 \alpha=4.0 ; 7 \beta-6 \beta=7.0 ; 6 \beta-7 \alpha=10.0 ; 7 \beta-7 \alpha=11.0 ; 6 \beta-6 \alpha=13.0 ; 9-10 \alpha=8.5 ; 9$ $10 \beta=9.6 ; 10 \alpha-10 \beta=10.8$. 


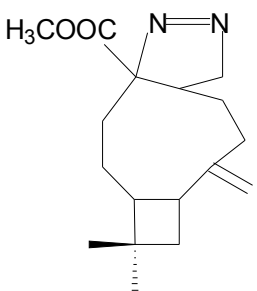

(6)

Analysis of caryophyllenic acids fractions after methylation with diazomethane often gave not two peaks, but 4 by the GLC-MS method. At the same time, the corresponding peak to the methyl ester of caryophyllenic acid (5) decreased. The compound to which the peak corresponded on a chromatogram with a retention index of 1731 was separated from the methyl ester of caryophyllenic acid by column chromatography on silica gel, using PE as the eluent with up to $3 \%$ diethyl ether.

The spectral data of the by-product of methylation coincided with the spectral data of pyrazoline methyl ester of caryophyllenic acid (5) [8]. On the chromatogram obtained by the GLC-MS method, as well as the peak of the compound with the retention index of 1747. the corresponding mass spectrum, which completely corresponds to the mass spectrum (6), but the intensity of this peak is 10 times smaller. Presumably, this is the peak of the methyl ester of isocaryophyllenic acid.

It is assumed that the presence of compound (5) in the extracts of plants of the genus Lychnophorinae leads to the development of antitumor, antinociceptive and anti-inflammatory activities. The alcohol extract of this plant, containing (5) inhibits the activity of xanthine oxidase [9].

\section{Conclusions}

6-Hydroxyisocaryophyllene was isolated from Betula pendula birch buds. Structure was determined by NMR spectroscopy. Caryophyllenic acid and isocaryphyllenic acid were discovered in the Betula grandifolia, B. albo-sinensis, B. fusca, B. obscura, B. litwinowii, B. hallii, B. grandifolia vegetative buds. The structure of the acids were determined by X-ray diffraction analysis. Thus, in the birch buds, together with the (E) isomers, there are also $(Z)$ isomers.

\section{Acknowledgements}

XRD study have been prepared at the X-ray Diffraction Centre of St.Petersburg State University.

\section{References}

1. Vedernikov, D.N., Roshchin V.I. Khim. Rast. Syr'ya, 2010. no. 4. pp. 67-75.

2. CrysAlisPro. Agilent Technologies. 2014. Version 1.171.37.35.

3. Sheldrick G.M. Acta Cryst., 2015. vol. 71. pp. 3-8. DOI: 10.1107/S2053229614024218

4. Dolomanov O.V., Bourhis L.J., Gildea R.J., Howard J.A.K, Puschmann H. J. Appl. Cryst., 2009. vol. 42. pp. 339341. DOI: $10.1107 / \mathrm{S} 0021889808042726$

5. Clericuzio M., Toma L., Vidari G. Eur.J.Org.Chem., 1999. pp. 2059-2065. DOI:10.1002/chin.199946180

6. Can Başer K.H., Demirci B. ARKIVOC, 2007. no. VII, pp.335-348. DOI: 10.3998/ark.5550190.0008.730

7. Vedernikov D.N., Roshchin V.I. Russ J. Bioorg. Chem., 2010. vol. 36. no. 7. pp. 899-908. DOI: $10.1134 / \mathrm{S} 1068162010070186$

8. Bohlmann F., Zdero C., Robinson H., King R.M. Phytochemistry, 1980. vol. 19. pp. 2381-2385. DOI: 10.1016/S0031-9422(00)91032-X

9. Costa Keles L., Isabel de Melo N., de Paula Aguiar G., Akemi Lima Wakabayash K., Eduardo de Carvalho C., Wilson Roberto, Cunha e Antônio, Eduardo Miller. Quim. Nova, 2010. vol. 33. no. 10. pp. 2245-2260. DOI:10.1590/S0100-40422010001000038

Received January 30. 2018

Revised March 23. 2018

For citing: Vedernikov D.N., Teplyakova S.V., Khoroshilova O.V. Khimiya Rastitel'nogo Syr'ya, 2018, no. 3, pp. $115-122$. DOI: $10.14258 /$ jcprm.2018033717. 